\title{
Creating Flexible Work Arrangements Through Idiosyncratic Deals
}

\author{
Severin Hornung \\ Technical University of Munich
}

\author{
Denise M. Rousseau \\ Carnegie Mellon University
}

\author{
Jürgen Glaser \\ Technical University of Munich
}

\begin{abstract}
A survey of 887 employees in a German government agency assessed the antecedents and consequences of idiosyncratic arrangements individual workers negotiated with their supervisors. Work arrangements promoting the individualization of employment conditions, such as part-time work and telecommuting, were positively related to the negotiation of idiosyncratic deals ("i-deals"). Worker personal initiative also had a positive effect on i-deal negotiation. Two types of i-deals were studied: flexibility in hours of work and developmental opportunities. Flexibility i-deals were negatively related and developmental i-deals positively related to work-family conflict and working unpaid overtime. Developmental i-deals were also positively related to increased performance expectations and affective organizational commitment, while flexibility i-deals were unrelated to either.
\end{abstract}

Keywords: individualized working conditions, negotiated flexibility, professional development opportunities, proactive behavior

Fostered by contemporary practices in organizing and managing the workplace, the active role of employees engaging in constructive behaviors beyond their prescribed job duties has garnered considerable scholarly attention (e.g., Crant, 2000; Griffin, Neal, \& Parker, 2007). Going beyond prosocial behavior and the overfulfillment of job requirements (Organ, 1988), employees have been shown to play a proactive role in shaping and customizing their on-the-job activities, work settings, and employment conditions (Lawler \& Finegold, 2001; Rousseau, 2001a; Wrzesniewski \& Dutton, 2001). This customization is at least partly achieved through idiosyncratic deals ("i-deals"), where individual employees negotiate with an employer to adapt work arrangements to better meet their personal needs (Rousseau, 2005). Traditionally, human resource practices in the developed world have downplayed customization in favor of standardization (Pearce, 2001). However, the liberalization of labor laws and reduction in collective bargaining (Farber \& Western, 2000), coupled with growing awareness of human capital's value to firms (Cappelli, 2000), have made it more normative to craft i-deals in lieu of or as a supplement to standardized employment conditions. Still to date, few empirical studies systematically investigate the prevalence, antecedents, or consequences of i-deals.

Severin Hornung and Jürgen Glaser, Institute of Psychology, Technical University of Munich, Munich, Germany; Denise M. Rousseau, Heinz School of Public Policy and Management and Tepper School of Business, Carnegie Mellon University.

This research was funded by the Institute of Psychology, Technical University of Munich and Denise M. Rousseau's H.J. Heinz II professorship.

Correspondence concerning this article should be addressed to Severin Hornung, Institute of Psychology, Technical University of Munich, Lothstrasse 17, D-80335, Munich, Germany. E-mail: hornung@wi.tum.de
The present study contributes to research on i-deals in several ways. Replicating previous results on the empirical distinctiveness of two commonly reported forms of i-deals-special flexibility in work hours and development opportunities (Rousseau, 2005; Rousseau \& Kim, 2006) - it examines individual proactivity and organizational work practices as antecedents to the negotiation of i-deals. It tests theoretical assumptions on both the joint and differential effects of these two forms of i-deals on employees' attitudes toward the organization, performance expectations, and conflict between work and private life. We focus on organizational and individual antecedents of i-deals as well as consequences relevant to both workers and the employer. Although theory identifies the specific factors investigated here to be critical for the negotiation and differential effects of i-deals (Rousseau, 2005), they are not comprehensive. Instead, we aspire to investigate factors relevant to i-deals in a highly regulated, bureaucratic setting where use of these arrangements is evidence of their potential for creating flexibility in work settings generally.

\section{I-Deals: Idiosyncratic Terms in Employment}

I-deals are a form of customization granting employees special conditions differing from peers doing similar work. Not limited to freelancers (Pink, 2002) or stars (Rosen, 1981), regular employees also seek out and bargain for special employment conditions that satisfy their personal needs and preferences. Although such deals can also arise at the time of hire or termination (Rousseau, 2005), the present study focuses on their emergence during ongoing employment. Defining features of i-deals include negotiation by individual workers and terms different from standard employment conditions (Rousseau, Ho, \& Greenberg, 2006). Another defining feature of i-deals is that they are intended to benefit both the employee and the firm by giving a valued worker something not otherwise obtainable through the firm's standard practices (Rous- 
seau, 2001a, 2005). Other forms of personalized employment arrangements, such as favoritism or cronyism, lack the mutually beneficial quality of i-deals where individual and organizational interests are served simultaneously (Rousseau, 2005). I-deals vary in content and scope from a single feature to the entire set of conditions composing the employment relationship, ranging from minor adjustments in hours or duties to highly customized, "idiosyncratic jobs" (Miner, 1987). Contents of i-deals involve a wide array of resources, from tangible and universalistic (e.g., payment, material goods) to abstract and particular (e.g., status, recognition, social support). Previous research has identified two especially widespread forms of i-deals: flexible scheduling of work hours and special opportunities for skill and career development (Rousseau, 2005; Rousseau \& Kim, 2006). The conditions that increase the likelihood of successfully negotiating such i-deals are the matter to which we now turn.

\section{Organizational Factors Influencing I-Deal Negotiation}

The ways an organization structures work can influence the likelihood that its employees successfully negotiate i-deals. Opportunities for i-deal negotiation may be limited in settings with interdependent and co-located employees doing similar work (Rousseau, 2005). Such settings may restrict employment conditions to standardized arrangements to avoid the justice issues that i-deals can raise among coworkers (Rousseau et al., 2006). I-deals may be harder to legitimate in such settings, being more readily interpreted as preferential treatment or favoritism. On the other hand, certain work structures can make it easier for workers to successfully negotiate employment conditions differing from their peers. Idiosyncrasy-promoting arrangements include remote or distributed work, non-comparability in work schedules or job duties, and more generally, the existence of various ways to structure work in the same organization.

A setting with an array of different work structures can promote the negotiation of i-deals by conveying a normative message to both workers and supervisors that idiosyncrasy in employment terms is legitimate (cf. Hochschild, 1997). Second, it can reduce negative reactions to i-deals on the part of co-workers by downplaying differences and limiting comparisons, a major obstacle to the negotiation of i-deals in highly standardized work settings. Third, such differences in employment conditions may contribute to worker motivation to seek i-deals in the first place. This is the case, for example, when a part-time worker negotiates the employer's financial support for night classes she knows full-time workers receive automatically. In sum, idiosyncrasy is enhanced when individualized arrangements are the norm, comparability of employment conditions among coworkers is limited, and/or differences in employment arrangements within the firm alert individuals to opportunities to negotiate individualized arrangements. Thus, we postulate that work structures promoting idiosyncrasy in employment conditions will be positively related to the extent to which individual workers successfully negotiate arrangements differing from peers.

Hypothesis 1: Work structures promoting idiosyncrasy in employment conditions are positively related to worker negotiation of flexibility i-deals and developmental i-deals.

\section{Personal Influences on I-deals}

Workers can be predisposed to negotiate i-deals for many reasons including recognition of their own value to the company, individual needs that differ from peers, and other personal factors that incline them to assert their preferences (Rousseau, 2005). In any case, negotiating special terms requires employees to voice their needs and to request or bargain for them. Similar to related constructs such as taking charge to initiate workplace change (Morrison \& Phelps, 1999) or the crafting of one's job to better fit personal needs (Wrzesniewski \& Dutton, 2001), negotiating an i-deal is one form of proactive behavior. General proactivity, as embodied in the concept of personal initiative (PI; Crant, 2000; Frese, Fay, Hilburger, Leng, \& Tag, 1997), fosters self-initiated, innovative problem solving, a potential precursor to i-deal negotiation. PI is conceptualized as a behavioral pattern characterized by the self-starting, persistent pursuit of personal and organizational goals and is associated with relatively stable individual differences (e.g., proactive personality; Frese et al., 1997). As proactive behavior, PI should predispose workers to devise, ask for, and negotiate arrangements benefiting themselves and their employers.

Hypothesis 2: Employee PI is positively related to negotiation of flexibility i-deals and developmental i-deals.

\section{The Aftermath of I-Deals}

By individualizing employment conditions according to their workers' personal needs, employers provide individuals a special contribution, often involving symbolic and social-emotional elements (e.g., trust, appreciation, personalization; Blau, 1964; Haas \& Deseran, 1981). In this manner, i-deals provide a basis for reciprocity between workers and the organization, with the negotiating supervisor usually acting as an agent of the latter (Gouldner, 1960; Levinson, 1965). This strengthened employment relationship results in a sense of obligation on the part of the employee to pay back the valuable contribution the employer has made (Casper \& Buffardi, 2004; Eisenberger, Armeli, Rexwinkel, Lynch, \& Rhoades, 2001; Rousseau, 2001b). A stronger relationship can also derive from an i-deal creating future opportunities with the firm that the worker would not otherwise have enjoyed. On the basis of both reciprocity and opportunities for future exchange, i-deals are expected to strengthen the employment relationship. As emotional attachment is an important consequence of a successful exchange of personalized contributions, we postulate that i-deals in general have a positive effect on employee attachment and, particularly, on affective commitment to the employer (Rhoades, Eisenberger, \& Armeli, 2001; Wayne, Shore, \& Liden, 1997).

Hypothesis 3: Flexibility and developmental i-deals are positively related to worker affective commitment.

On the other hand, the impact i-deals have on both the recipient and the employer depends on the nature of the i-deal and the meaning ascribed to it. Previous research has found flexibility and developmental i-deals to be the most common, their incidence exceeding deals involving other work conditions such as pay or benefits (Rousseau, 2005). However, flexibility and developmental i-deals can differ in their consequences for worker and employer 
depending on the resources involved and experiences encountered in the i-deal's aftermath.

The leeway workers enjoy from negotiating flexibility in their work hours can lead to better coordination and integration of work and private life-family responsibilities being a major reason that individuals seek flexibility (Bailey \& Kurland, 2002; Cullen, Kordey, Schmidt, \& Gaboardi, 2003; Ford, Heinen, \& Langkamer, 2007; Mokhtarian, Bagley, \& Salomon, 1998; Thornthwaite, 2004). Employees may use greater personal control over their work schedule to counterbalance peak and slack periods and to work in accordance with their personal preferences (e.g., starting late in the morning), increasing productivity while reducing the stress involved in doing their jobs (Dunham, Pierce, \& Castaneda, 1987; Steward, 2000; Tietze \& Musson, 2003).

Nonetheless, the fact that workers in contemporary firms commonly face increasing performance pressures in response to market conditions and demands for efficiency can make it difficult for workers to seek flexibility and for employers to grant it (Rousseau, 2006). Negative consequences can befall i-dealers whose flexible hours depart from widely held work norms (e.g., negotiating shorter work days in a firm where advancement requires putting in long hours). A worker who approaches the work role differently from peers-in terms of hours worked or availability to clients or colleaguesunintentionally may signal a lack of commitment to high performance (Landers, Rebitzer, \& Taylor, 1996). Workers who negotiate flexible work arrangements can be subject to subsequent lower performance evaluations due to their nonconforming work practices (Perlow, 1997). This is particularly the case when performance is measured subjectively or not otherwise prorated based on the altered duties, hours, or other arrangements their i-deal entailed (Rousseau, 2005). High performers who successfully negotiated i-deals to balance work and family demands have seen their career opportunities subsequently diminished, as they are judged less committed or valuable than peers without such i-deals (Perlow, 1997). Although flexible arrangements might reduce work-family conflict, they also can diminish what the employer comes to expect from workers with these arrangements. This is particularly the case where flexible arrangements restrict worker visibility to their supervisor or their actual hours on the job. As a result of worker exercise of greater control over work time, we postulate that flexibility i-deals will be negatively related to both workfamily conflict and overtime hours. Further, as flexibility i-deals signal both worker concern and employer consent for balancing work and private life, we expect employees with these i-deals to experience little pressure to increase their performance.

Hypothesis 4a: Flexibility i-deals are negatively related to work-family conflict.

Hypothesis 4b: Flexibility i-deals are negatively related to increased performance expectations.

Hypothesis 4c: Flexibility i-deals are negatively related to overtime hours worked.
Developmental i-deals, in contrast, involve an exchange of resources prone to reinforce or strengthen the worker's involvement and performance in the firm (Foa \& Foa, 1975). Analogous to March and Simon's (1958) distinction between the decisions to participate and to produce, flexibility i-deals are more in line with retaining the services of a worker at a standard level of performance, while developmental i-deals both motivate and reward high performance. Employees negotiating special assignments or training to develop particular competencies may increase their value and standing in the eyes of the employer over time while enhancing their own performance and commitment to the organization. We postulate that developmental i-deals relate to both increased performance expectations and actual employee contributions in terms of extra hours invested in the job. Moreover, we expect that the higher work involvement associated with developmental i-deals increases the likelihood that work will interfere with the employee's family life.

Hypothesis 5c: Developmental i-deals are positively related to work-family conflict.

Hypothesis 5a: Developmental i-deals are positively related to increased performance expectations.

Hypothesis 5b: Developmental i-deals are positively related to overtime worked.

\section{Method \\ Organizational Setting}

The study was conducted in the public tax administration of the German state of Bavaria as part of an evaluation of the psychological impact of new work arrangements. With over 100 local offices, the administration employed about 20,000 tenured civil servants, roughly one-third of whom used their legally established right to work part-time (i.e., below 40 hours a week). Job qualifications, pay, career paths, and retirement age were highly regulated.

Two years prior to the study, the tax administration introduced a telecommuting program, allowing workers to work at home as well as in the office. This program was part of a larger effort to improve the structural rigidity of public employment and employees' quality of work life (Landler, 2007) as well as to help employees cope with an ongoing increase in their workload as the administration's aging workforce retired. Two divisions participated in the program: office accounting, where clerks process taxpayer forms; and field accounting, where auditors spend considerable time working away from the office examining businesses' tax records. In office accounting, total participants were restricted to 200 giving preference to those with social or healthrelated reasons (e.g., small children, caring for relatives, disabilities). Participating clerks were required to work in the office a minimum of 1 day per week. In field accounting, no restrictions applied. Auditors, who worked 3 days on average in the firms they inspected, were required to work in the tax office only once every 2 weeks.

In both divisions, individual program participation was granted for 3 years and home offices were fully equipped by the organization. Supervisors were required to specify daily hours in which 
telecommuting employees were to be accessible in their home offices to colleagues and the public via telephone or e-mail. During the study, 200 clerks in office accounting and 740 auditors in field accounting participated in the program.

\section{Sample}

Surveys were administered via internal mail service to be completed voluntarily and on the job. In addition to participants in the telecommuting program, the human resource department selected comparison groups in conventional work arrangements on the basis of job and demographic similarity. For economic reasons, the ratio of telecommuters and comparison groups was set to $1: 1$ for office accounting and 2:1 for field accounting, a total of 1,510 distributed surveys. Questionnaires were pre-coded for division and telecommuting status, which was verified by asking participants also to provide this information. No discrepancy between pre-codes and participant reports was detected. The four subgroups will be referred to as home-based workers (telecommuters in office accounting), office workers (comparison group in office accounting), home-based fieldworkers (telecommuters in field accounting), and office-based fieldworkers (comparison group in field accounting). After deleting incomplete surveys, 887 employees provided usable data, yielding response rates between $53.0 \%$ and $65.0 \%$ in the four subgroups and an overall participation rate of $58.7 \%$. All were lifetime employees performing computer-based tasks. Table 1 describes each subgroup. Chi-square and $t$ tests compared categorical (gender, part-time) and continuous variables (age, tenure) across subgroups, finding no significant differences between telecommuters and conventional workers. Compared with office workers, fieldworkers tended to be men, older, and fulltime.

\section{Measures}

All multiple-item measures used a 5-point Likert scale ranging from 1 (not at all) to 5 (to a very great extent). Work structures facilitating idiosyncrasy in employment conditions were operationalized by using three dichotomous variables.

Part-time. Working part-time provides individuals employment conditions (hours, promotion, and development opportunities) different from the standard arrangements of full-timers. As such they are non-comparable with the majority of employees, and in a formal position that limits their opportunities. Such conditions are expected to facilitate idiosyncrasy. Participants indicated whether they were employed full- or part-time and also reported their contractual total work hours, dummy coded part-time (1) and full-time (0).

Telecommuting. By virtue of the program's focus on creating workplace flexibility, individual telecommuters are better positioned to obtain supervisor permission for employment arrangements differing from their peers. The program itself signals flexibility's legitimacy, while its newness and lack of well-established routines provide opportunities for customization. Because telecommuters spent considerable time outside the tax office, their arrangements also are less visible to coworkers. Together these features are expected to promote idiosyncrasy in the employment conditions telecommuters enjoy. Participation in the telecommuting program was obtained from the questionnaire's pre-coding and verified by employee self-report, dummy coded telecommuting (1) and conventional work (0).

Fieldwork. Although fieldwork necessitated spending time in auditees' workplaces, idiosyncrasy should be enhanced by the distributed nature of this work and the limited time fieldworkers spend in the tax office itself, both of which limit coworker scru-

Table 1

Description of Accounting Employees Working Inside and Outside the Office

\begin{tabular}{|c|c|c|}
\hline Group & Office accounting division & Field accounting division \\
\hline \multirow{10}{*}{$\begin{array}{l}\text { Conventional work } \\
\text { form }\end{array}$} & Office workers, $N=106$ (response rate: $53.0 \%$ ) & Office-based fieldworkers, $N=206$ (response rate: $55.7 \%$ ) \\
\hline & Demographics: & Demographics: \\
\hline & Gender: $58.5 \%$ female, $41.5 \%$ male & Gender: $16.5 \%$ female, $83.5 \%$ male \\
\hline & Age: 43.01 years & Age: 44.21 years \\
\hline & Organizational tenure: 18.11 years & Organizational tenure: 18.04 years \\
\hline & Working-time (contract): & Working-time (contract): \\
\hline & Full-time: $64.2 \%$, average $40.0 \mathrm{hr} /$ week & Full-time: $87.9 \%$, average $40.0 \mathrm{hr} /$ week \\
\hline & Part-time: $35.8 \%$, average $26.0 \mathrm{hr}$; range $16.0-36.0$ & Part-time: $12.1 \%$, average $28.0 \mathrm{hr}$; range $16.0-36.0$ \\
\hline & Location of work (\% of working time): & Location of work (\% of working time): \\
\hline & Tax-office: $100.0 \%$ & Tax-office: $40.0 \%$, field (organizations): $60.0 \%$ \\
\hline \multirow{11}{*}{$\begin{array}{l}\text { Telecommuting } \\
\text { program }\end{array}$} & Home-based workers, $N=130$ (response rate: $65.0 \%$ ) & Home-based fieldworkers, $N=445$ (response rate: $60.1 \%$ ) \\
\hline & Demographics: & Demographics: \\
\hline & Gender: $56.2 \%$ female, $43.8 \%$ male & Gender: $12.4 \%$ female, $87.6 \%$ male \\
\hline & Age: 41.32 years & Age: 44.13 years \\
\hline & Organizational tenure: 15.81 years & Organizational tenure: 16.79 years \\
\hline & Telecommuting since: 1.45 years & Telecommuting since: 1.87 years \\
\hline & Working-time (contract): & Working-time (contract): \\
\hline & Full-time: $60.0 \%$, average $40.0 \mathrm{hr} /$ week & Full-time: $90.8 \%$, average $40.0 \mathrm{hr} /$ week \\
\hline & Part-time: $40.0 \%$, average $23.0 \mathrm{hr}$; range $10.0-36.0$ & Part-time: $9.2 \%$, average $29.5 \mathrm{hr}$; range $20.0-36.0$ \\
\hline & Location of work (\% of working time): & Location of work (\% of working time): \\
\hline & Tax-office:: $21.1 \%$, home-office: $78.9 \%$ & Tax-office: $15.9 \%$, field (organizations): $58.9 \%$, home-office: $25.2 \%$ \\
\hline
\end{tabular}


tiny. Division membership was assessed via questionnaire precoding and verified by employee self-report, dummy coded field division (1) and office division (0). In addition (not included in our analyses), respondents also reported hours per week typically spent in the tax office, home office, or in the field visiting the businesses they audited. Table 1 reports the average distribution of time across workplaces for the groups studied.

I-deals. Using a German translation of Rousseau's measures (e.g., Rousseau \& Kim, 2006), employees indicated the extent to which in their current jobs they had "asked for and successfully negotiated individual arrangements different from their peers" in terms of flexibility i-deals (two items) and development i-deals (four items). Flexibility items included "Flexibility in starting and ending the workday" and "Individually customized work schedule." Developmental items were "On-the-job activities," "Training opportunities," "Special opportunities for skill development," and "Career development."

PI. PI was assessed via the original German version of Frese et al.'s (1997) seven-item scale. Items include "Whenever there is a chance to get actively involved, I take it" and "I use opportunities quickly in order to attain my goals."

Affective commitment. The German version (Büssing, 2002) of a five-item measure (subscale from Penley \& Gould's (1988) Organizational Commitment scale) tapped workers' positive affective attachment to the organization. Items include "I am dedicated to this organization" and "It is my personal responsibility to help this organization achieve success."

Increased performance expectations. Three items measured whether employees believed that their direct supervisor's expectations for them had increased with respect to "quality of work," "meeting deadlines," and "attaining goals." The wording of this customized measure reflected one motivation for the survey, understanding how program participation related to staff perceptions of the tax administration's increasing performance demands.

Work-family conflict. Work interference with family and personal life was measured with a German version of Netemeyer, Boles, and McNurrian's (1996) five-item scale, containing statements such as "The demands of my work interfere with my home and family life," and "The amount of time my job takes up makes it difficult to fulfill family responsibilities."
Overtime. Participants were requested to report their average weekly hours of voluntary, unpaid overtime as a behavioral indicator of their contribution to the organization.

Demographic variables. Along with a dichotomous gender measure, age and organizational tenure were obtained by participants recording the appropriate number of years and months, which we converted to a metric scale (e.g., 10.5 equals 10 years and 6 months).

\section{Results}

\section{Scale Analyses}

Scale analyses were conducted in several steps by using multigroup CFA to assess (a) our measures' factor structure, (b) measurement invariance between subgroups permitting testing hypotheses in one combined sample, and (c) extent of common method bias. Results indicate good psychometric quality, comparability of subgroups, and modest common method bias (Appendix A). Descriptive statistics, correlations, and reliabilities for the combined sample are shown in Table 2. Note that the reported extent of flexibility i-deals is moderate $(M=2.33)$, while development i-deals are lower $(M=1.64)$. This pattern reflects two features of the study's context: (a) attempts to make civil-service work more attractive by supporting workplace flexibility and (b) financial and other constraints on developmental opportunities. The demographic variables gender and age correlate with i-deals and thus are controlled in our analyses.

\section{Model Testing}

Hypotheses were tested via a structural equation model, based on the measurement models and additional manifest variables (Figure 1). For the one-item measure of Overtime, an assumed reliability of .80 was modeled by using a common procedure restricting error variance and the factor loading of one-indicator latent variables (James, Mulaik \& Brett, 1982; Kenny, 1979). Goodness-of-fit measures displayed in Figure 1 indicate satisfactory model fit. We note that in our sample female employees are

Table 2

Correlations and Descriptive Statistics for Accounting Employees $(N=887)$

\begin{tabular}{|c|c|c|c|c|c|c|c|c|c|c|c|c|c|c|c|}
\hline Variable & $\#$ & $M / \%$ & $S D$ & 1 & 2 & 3 & 4 & 5 & 6 & 7 & 8 & 9 & 10 & 11 & 12 \\
\hline 1 Gender (f) & 1 & $25.1 \%$ & & - & & & & & & & & & & & \\
\hline 2 Age & 1 & 43.61 & 8.34 & $-.29^{* *}$ & - & & & & & & & & & & \\
\hline 3 Organizational Tenure & 1 & 17.11 & 10.75 & $-.12^{* * *}$ & $.64^{* * *}$ & - & & & & & & & & & \\
\hline 4 Part-time & 1 & $17.5 \%$ & & $.53^{* *}$ & $-.12^{* *}$ & -.04 & - & & & & & & & & \\
\hline 5 Telecommuting & 1 & $64.8 \%$ & & $-.09^{* *}$ & -.02 & -.06 & .05 & - & & & & & & & \\
\hline 6 Fieldwork & 1 & $73.4 \%$ & & $-.44^{* *}$ & $.11^{* *}$ & .01 & $-.32^{* *}$ & $.12^{* *}$ & - & & & & & & \\
\hline 7 Personal Initiative & 7 & 3.72 & 0.50 & -.05 & $.10^{* *}$ & .06 & $-.09^{*}$ & $.17^{* * *}$ & .00 & .85 & & & & & \\
\hline 8 I-Deals Flexibility & 2 & 2.33 & 1.33 & $.24^{* * *}$ & $-.13^{* *}$ & -.04 & $.37^{* *}$ & $.25^{* *}$ & $-.29^{* *}$ & $.10^{* * *}$ & .82 & & & & \\
\hline 9 I-Deals Development & 4 & 1.64 & 0.75 & -.00 & $-.10^{* *}$ & -.04 & $.09^{* *}$ & .06 & -.05 & $.10^{* * *}$ & $.40^{* *}$ & .87 & & & \\
\hline 10 Work-Family Conflict & 5 & 2.10 & 0.79 & $.07^{*}$ & -.05 & -.02 & .07 & $-.29^{* *}$ & $-.10^{* *}$ & $-.19^{* * *}$ & -.05 & $.09^{* *}$ & .92 & & \\
\hline 11 Affective Commitment & 5 & 3.01 & 0.71 & $-.07^{*}$ & $.23^{* *}$ & $.18^{* * *}$ & -.06 & $.08^{*}$ & $.08^{*}$ & $.17^{* * *}$ & -.02 & $.07^{*}$ & -.06 & .75 & \\
\hline 12 Performance Expectations & 3 & 2.74 & 0.89 & -.00 & $.09^{* * *}$ & $.08^{*}$ & .03 & $-.24^{* * *}$ & $-.11^{* * *}$ & .02 & .02 & .06 & .06 & .03 & .86 \\
\hline 13 Overtime & 1 & 1.67 & 1.91 & .05 & .05 & .04 & .03 & -.06 & -.05 & $.14^{* * *}$ & -.04 & .07 & $.08^{*}$ & $.08^{*}$ & $.10^{* *}$ \\
\hline
\end{tabular}

${ }^{*} p<.05$.

$p<.01$. 


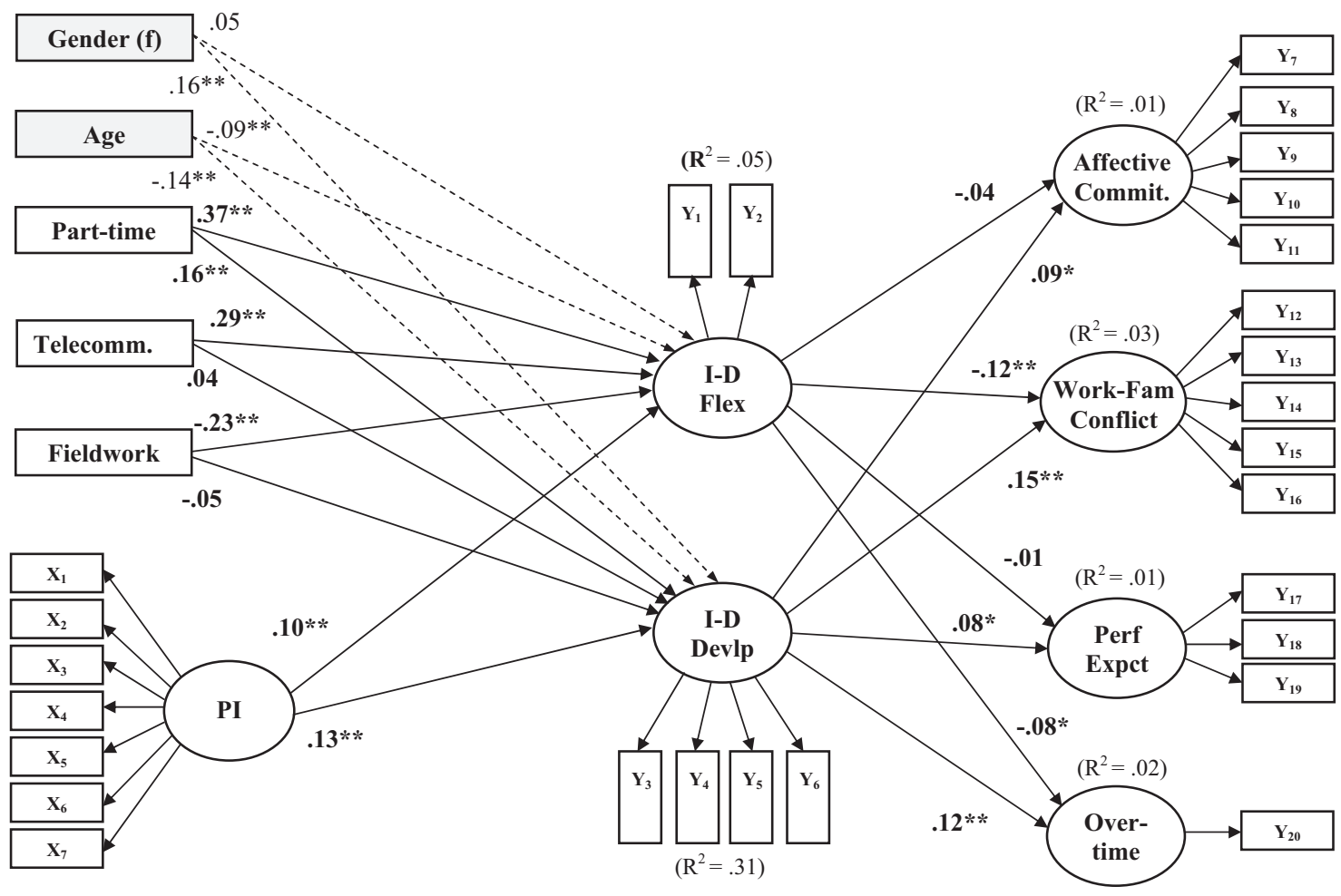

Figure 1. Structural model $(N=887)$. Model fit: $\chi^{2}(435)=1,323.68^{* *} ; \chi^{2} / d f=3.04$; incremental fit index $=$ .92 ; Tucker-Lewis index $=.91 ;$ comparative fit index $=.92$; root-mean-square error of approximation $=.048$; $95 \%$ confidence interval $=.045, .051$. Intercorrelations of independent variables are omitted from the diagram; control variables are shaded gray. PI = personal initiative; I-D = idiosyncratic deals; flex = flexible scheduling; devlp $=$ developmental opportunities; perf expct $=$ performance expectations; affective commit. $=$ affective commitment. ${ }^{*} p<.05 .{ }^{* *} p<.01$.

more likely to negotiate flexibility i-deals, while age relates negatively to both types of i-deal.

Hypothesis 1, that work practices promoting idiosyncrasy have a positive effect on i-deal negotiation, was tested with three dummy-coded manifest variables, Part-Time, Telecommuting, and Fieldwork. Accordingly, Part-Time had positive, significant effects on Flexibility $(\beta=.37, p<.01)$ and Developmental I-Deals $(\beta=.16, p<.01)$. Telecommuting had a positive, significant effect on Flexibility I-Deals $(\beta=.29, p<.01)$ but not on Developmental I-Deals $(\beta=.04, n s)$. Contrary to expectations, Fieldwork had a significant negative effect on Flexibility I-Deals $(\beta=-.23, p<.01)$ but no significant effect on Developmental I-Deals $(\beta=-.05, n s)$. Evidence for Hypothesis 1 therefore is mixed and warrants further discussion below.

Hypothesis 2 was modeled by paths from PI to both forms of i-deals with positive, significant effects on both Flexibility $(\beta=$ $.10, p<.01$ ) and Developmental I-Deals $(\beta=.13, p<.01)$, fully supporting Hypothesis 2. Hypothesis 3 posited positive effects of i-deals on Affective Commitment and was partially supported (Developmental $\beta=.09, p<.05$; Flexibility I-Deals $\beta=-.05$, $n s)$. Hypothesis 4 and Hypothesis 5 postulated differential individual and organizational consequences of the two forms of i-deals. Consistent with Hypotheses $4 \mathrm{a}$ and 4c, Flexibility I-Deals related significantly and negatively to both Work-Family Conflict ( $\beta=$ $-.12, p<.01)$ and Overtime $(\beta=-.08, p<.05)$. Hypothesis $4 \mathrm{~b}$, that Flexibility I-Deals relate negatively to Increased Performance Expectations, was not supported $(\beta=-.01, n s)$. Consistent with Hypotheses 5a, 5b, and 5c, Developmental I-Deals had significant, positive effects on Work-Family Conflict $(\beta=.15, p<.01)$, Increased Performance Expectations $(\beta=.08, p<.05)$, and Overtime $(\beta=.12, p<.01)$. Following common practice, we compared our hypothesized model with several alternative causal models (Appendix B), none of which proved to be superior to our model.

\section{Discussion}

Our study demonstrates that i-deals occur even in settings such as the civil service known for personnel rules and standardization. It also suggests that work structures can foster as well as inhibit i-deals. Part-timers demonstrated greater customization of their employment via i-deals than did full-timers with regard to both flexible scheduling and developmental opportunities. The latter result may be partly due to the lower level of formal development available to part-timers via standard organizational practices (Hochschild, 1997; Perlow, 1997), a limitation part-timers can overcome via negotiation. Part-timers may have capitalized on their lack of comparability with full-timers to further negotiate flexibility with respect to work hours. Telecommuters also used their leeway to work at home as a basis to negotiate more far- 
reaching flexibility beyond the scope and rules of the program. Interviews with supervisors indicated that this "add-on" flexibility involved customized scheduling and occasional suspension of mandatory times at home or in the office. Feldman and Pentland (2003) provided evidence of the ways individual workers shape how personnel routines are executed. Employees can create opportunities beyond personnel policy's formal strictures by expanding and re-interpreting its scope via the negotiation of i-deals (Rousseau, 2006). Such may be particularly true for newly established practices such as telecommuting in this study.

Other work structure effects were contrary to our hypotheses. Field accountants, with jobs characterized by high autonomy, reported less flexibility via i-deals than did their office-based counterparts. This may be due to time constraints clients impose on auditors, by limiting work to weekdays and conventional office hours (Glaser \& Hornung, 2004). Job crafting, however, may be an additional explanation, as field accountants are less closely monitored by their supervisors and may be able to create their own flexible schedule without seeking permission for it (Rousseau, 2005; Wrzesniewski \& Dutton, 2001). The lack of an effect from telecommuting or fieldwork status on developmental i-deals may be due to the organization's personnel practices, with limited possibilities for training, career development, and promotion. In such cases, workers whose part-time status restricts formal opportunities for training and development may be able to negotiate opportunities commensurate with those of their full-time counterparts, while telecommuters and fieldworkers may generally realize the developmental opportunities afforded full-timers, leaving little room for negotiation.

Although more research on organizational influences is needed, results call attention to the opportunities work context can provide to negotiate i-deals as well as the constraints it can impose. Our findings caution against treating i-deals as monolithic: They take various forms differing in their incidence depending on contextual factors. It is clear that more theory-building is needed with regard to how work structures and other features of the organizational context influence the importance workers ascribe to i-deals, the employer's willingness to grant them, and their visibility and relevance to coworkers. In contrast, the evidence for proactive behavior as an individual antecedent of i-deals is far less ambiguous than that for organizational antecedents. As expected, the self-starting and persistent pursuit of goals, characterizing high levels of PI, can take the form of seeking and successfully negotiating i-deals.

Consistent with theory (Rousseau, 2005; Rousseau et al., 2006), the two types of i-deals studied were differentially related to employee outcomes. As expected, workers with flexibility i-deals worked less unpaid overtime and had less work-family conflict than those without this i-deal. However, this i-deal's expected consequence of lower performance expectations turned out to be a non-issue. One explanation for the lack of a negative effect of flexibility i-deals on performance expectations lies with organization-specific practices. The tax administration offered its workers few performance-based rewards and promotion opportunities, which in turn might have limited the downside of flexibility i-deals in contrast to previous findings in the United States (cf. Perlow, 1997). Note also that our measure tapped increased performance expectations rather than their overall level. Thus though we demonstrate that perceived expectations did not increase with flexibility i-deals, we cannot test whether they actually declined in the deals' aftermath. Moreover, flexibility i-deals were not related to affective commitment, despite the employer's policy of granting them to create a more attractive workplace. Perhaps more time needed to elapse before certain consequences, positive or negative, became evident. On the other hand, the tax administration's active efforts to legitimate flexibility by creating a critical mass of fellow workers enjoying its benefits may have caused flexibility to be seen as normative rather than idiosyncratic, reducing its signal value as an indicator of employment quality. In contrast, developmental i-deals demonstrated positive effects on worker commitment and contributions to the organization, while exacerbating work-life conflict. Our results suggest that the consequences of i-deals depend on the type of i-deal and the circumstances of its creation.

\section{Limitations}

Several limitations warrant note. We cannot make causal inferences because our data are cross-sectional. Longitudinal studies are needed to identify appropriate time lags for effects and their causal order. Generalizability is also a concern due to national differences in practices regarding individualized employment arrangements (Rousseau \& Schalk, 2000), our distinctive governmental setting, and the survey's timing to coincide with a program intended to legitimate flexibility. Ranging between one and three percent, this study's explained variance of dependent variables is fairly small, attributable to low variance in the i-deals measures due to highly standardized practices in public employment. Taking into account the relative novelty of the subject and constructs under study as well as the ongoing methodological discussion on statistical significance versus variance explained in field research, we regard this to be a limitation but not a major concern (e.g., Fichman, 1999). Also, the translation of i-deal measures developed in the United States offers the advantages of standardization and comparability. However, it may be better to customize the assessment to capture setting-specific i-deals.

As i-deals are a relatively new construct, this study raises issues for future organizational research, including (a) closer inspection of how work structures impact i-deals; (b) investigation of the impact of peers, their perceptions, and own employment arrangements on i-deal negotiation and its aftermath; (c) examination of the "i-deal that wasn't," that is, antecedents and consequences of unsuccessful attempts to negotiate individual arrangements; (d) supervisor motives in granting i-deals; (e) identification and study of other i-deal types, antecedents, and consequences; and (f) simultaneous consideration of employee and supervisory perspectives.

\section{Conclusion}

Idiosyncratic deals are not limited to workers in competitive markets or non-bureaucratic firms. The social forces motivating i-deals impact workers broadly, including dual wage/career families challenged to balance work and home life (Klein, Berman, \& Dickson, 2000; Kochan, 2005; Lee, MacDermid, \& Buck, 2000) and limitations on the developmental opportunities that workers increasingly value (Arthur \& Rousseau, 1996). Observing idiosyncratic arrangements in the German civil service affirms that i-deals 
are a widespread phenomenon, broadly applicable for work-life balance and workforce motivation and development.

\section{References}

Arthur, M. B., \& Rousseau, D. M. (1996). The boundaryless career: A new employment principle for a new organizational era. New York: Oxford.

Bailey, D. E., \& Kurland, N. B. (2002). A review of telework research: Findings, new directions, and lessons for the study of modern work. Journal of Organizational Behavior, 23, 383-400.

Blau, P. M. (1964). Exchange and power in social life. New York: Wiley. Büssing, A. (2002). Trust and its relation to commitment and involvement in work and organisations. Journal of Industrial Psychology, 28, 33-39.

Byrne, B. M. (1998). Structural equation modeling with LISREL, PRELIS, and SIMPLIS: Basic concepts, applications, and programming. Mahwah, NJ: Erlbaum.

Cappelli, P. (2000). A market-driven approach to retaining talent. Harvard Business Review, 78, 103-111.

Casper, W. J., \& Buffardi, L. C. (2004). The impact of work/life benefits and perceived organizational support on job pursuit intentions. Journal of Vocational Behavior, 65, 391-410.

Cheung, G. W., \& Rensvold, R. B. (2002). Evaluating goodness-of-fit indexes for testing measurement invariance. Structural Equation Modeling, 9, 233-255.

Crant, J. M. (2000). Proactive behavior in organizations. Journal of Management, 26, 435-462.

Cullen, K., Kordey, N., Schmidt, L., \& Gaboardi, E. (2003). Work and family in the ework era. Amsterdam: IOS Press.

Dunham, R. B., Pierce, J. L., \& Castaneda, M. B. (1987). Alternative work schedules: Two field quasi-experiments. Personnel Psychology, 40, 215-242.

Eisenberger, R., Armeli, S., Rexwinkel, B., Lynch, P. D., \& Rhoades, L. (2001). Reciprocation of perceived organizational support. Journal of Applied Psychology, 86, 42-51.

Farber, H. S., \& Western, B. (2000). Roundup the usual suspects: The decline of unions in the private sector, 1973-1998 [Working Paper \#437]. Princeton, NJ: Industrial Relations Section, Princeton University.

Feldman, M. S., \& Pentland, B. (2003). Reconceptualizing organizational routines as a source of flexibility and change. Administrative Science Quarterly, 48, 94-120.

Fichman, M. (1999). Variance explained: Why size does not (always) matter. In B. M. Staw \& R. M. Sutton (Eds.), Research in organizational behavior (Vol. 21, pp. 295-331). Amsterdam: Elsevier.

Foa, U. G., \& Foa, E. B. (1975). Societal structures of the mind. Springfield, IL: Charles C. Thomas.

Ford, M. T., Heinen, B. A., \& Langkamer, K. L. (2007). Work and family satisfaction and conflict: A meta-analysis of cross-domain relations. Journal of Applied Psychology, 92, 57-80.

Frese, M., Fay, D., Hilburger, T., Leng, K., \& Tag, A. (1997). The concept of personal initiative: Operationalization, reliability, and validity in two German samples. Journal of Occupational and Organizational Psychology, 70, 139-161.

Glaser, J., \& Hornung, S. (2004). Mitarbeiterorientierte Flexibilisierung von Arbeit im öffentlichen Dienst. Eine arbeits- und organisationspsychologische Evaluation der Telearbeit in der bayerischen Steuerverwaltung [Employee-oriented flexibilization of work in the public service. A work- and organizational psychological evaluation of telework in the Bavarian tax administration] (Report No. 77). München, Germany: Technical University of Munich, Chair of Psychology.

Gouldner, A. W. (1960). The norm of reciprocity: A preliminary statement. American Sociological Review, 25, 161-178.

Griffin, M. A., Neal, A., \& Parker, S. K. (2007). A new model of work role performance: Positive behavior in uncertain and interdependent contexts. Academy of Management Journal, 50, 327-347.
Haas, D. F., \& Deseran, F. A. (1981). Trust and symbolic exchange. Social Psychology Quarterly, 44, 3-13.

Hochschild, A. R. (1997). Time bind: When work becomes home and home becomes work. New York: Henry Holt.

James, L. R., Mulaik, S. S., \& Brett, J. M. (1982). Causal analysis. Beverly Hills, CA: Sage.

Kenny, D. A. (1979). Correlation and causality. New York: Wiley.

Klein, K. J., Berman, L., \& Dickson, M. (2000). May I work part time? An exploration of predicted employer responses to employee requests for part time work. Journal of Vocational Behavior, 57, 85-101.

Kline, R. B. (1998). Principles and practice of structural equation modeling. New York: Guilford Press.

Kochan, T. A. (2005). Rediscovering the American dream. Cambridge, MA: MIT Press.

Landers, R. M., Rebitzer, J. B., \& Taylor, L. J. (1996). Rat race redux: Adverse selection in the determination of work hours in law firms. American Economic Review, 86, 329-348.

Landler, M. (2007, February 6). Germany agonizes over a brain drain. New York Times, p. A10.

Lawler, E. E., III, \& Finegold, D. (2001). Individualizing the organization: Past, present, and future. Organizational Dynamics, 29, 1-15.

Lee, M. D., MacDermid, S. M., \& Buck, M. L. (2000). Organizational paradigms of reduced-load work: Accommodation, elaboration, and transformation. Academy of Management Journal, 43, 1211-1226.

Levinson, H. (1965). Reciprocation: The relationship between man and organization. Administrative Science Quarterly, 9, 370-390.

Lievens, F., \& Anseel, F. (2004). Confirmatory factor analysis and invariance of an organizational citizenship behaviour measure across samples in a Dutch-speaking context. Journal of Occupational and Organizational Psychology, 77, 299-306.

March, J. G., \& Simon, H. A. (1958). Organizations. New York: Wiley.

Miner, A. S. (1987). Idiosyncratic jobs in formalized organizations. Administrative Science Quarterly, 32, 327-351.

Mokhtarian, P. L., Bagley, M. N., \& Salomon, I. (1998). The impact of gender, occupation, and presence of children on telecommuting motivations and constraints. Journal of the American Society for Information Science, 49, 1115-1134.

Morrison, E. W., \& Phelps, C. C. (1999). Taking charge at work: Extrarole efforts to initiate workplace change. Academy of Management Journal, 42, 403-419.

Netemeyer, R., Boles, J., \& McNurrian, R. (1996). Development and validation of work-family conflict and family-work conflict scales. Journal of Applied Psychology, 81, 400-410.

Organ, D. W. (1988). Organizational citizenship behavior: The good soldier syndrome. Lexington, MA: Lexington Books.

Pearce, J. L. (2001). Organization and management in the embrace of government. Mahwah, NJ: Erlbaum.

Penley, L. E., \& Gould, S. (1988). Etzioni's model of organizational involvement: A perspective for understanding commitment to organizations. Journal of Organizational Behavior, 19, 217-233.

Perlow, L. (1997). Finding time: How corporations, individuals and families can benefit from new work practices. Ithaca, NY: Cornell.

Pink, D. (2002). Free-agent nation: The future of working for yourself. New York: Warner.

Podsakoff, P. M., MacKenzie, S. B., Lee, J.-Y., \& Podsakoff, N. P. (2003). Common method bias in behavioral research: A critical review of the literature and recommended remedies. Journal of Applied Psychology, 88, 879-903.

Preacher, K. J. (2006). Quantifying parsimony in structural equation modeling. Multivariate Behavioral Research, 41, 227-259.

Rhoades, L., Eisenberger, R., \& Armeli, S. (2001). Affective commitment to the organization: The contribution of perceived organizational support. Journal of Applied Psychology, 86, 825-836. 
Rosen, S. (1981). The economics of superstars. American Economic Review, 71, 845-858.

Rousseau, D. M. (2001a). Idiosyncratic deals: Flexibility versus fairness? Organizational Dynamics, 29, 260-271.

Rousseau, D. M. (2001b). Schema, promise and mutuality: The building blocks of the psychological contract. Journal of Occupational and Organizational Psychology, 74, 511-541.

Rousseau, D. M. (2005). I-deals: Idiosyncratic deals employees bargain for themselves. New York: M. E. Sharpe.

Rousseau, D. M. (2006). The shift in risk from employers to workers in the new employment relationship. E. E. Lawler III \& J. O'Toole (Eds.), America at work: Choices and challenges (pp. 153-172). New York: Palgrave Macmillan.

Rousseau, D. M., Ho, V. T., \& Greenberg, J. (2006). I-deals: Idiosyncratic terms in employment relationships. Academy of Management Review, 31, 977-994.

Rousseau, D. M., \& Kim, T. G. (2006. September). When workers bargain for themselves: Idiosyncratic deals and the nature of the employment relationship. Paper presented at the British Academy of Management Conference, Belfast, Ireland.

Rousseau, D. M., \& Schalk, R. (2000). Psychological contracts in employment: Cross-national perspectives. Newbury Park, CA: Sage.

Steward, B. (2000). Changing times. The meaning, measurement and use of time in teleworking. Time \& Society, 9, 57-74.

Thornthwaite, L. (2004). Working time and work-family balance: A review of employees' preferences. Asia Pacific Journal of Human Resources, 42, 166-184.

Tietze, S., \& Musson, G. (2003). The times and temporalities of homebased telework. Personnel Review, 32, 438-455.

Wayne, S. J., Shore, L. M., \& Liden, R. C. (1997). Perceived organizational support and leader-member exchange: A social exchange perspective. Academy of Management Journal, 40, 82-111.

Wrzesniewski, A., \& Dutton, J. E. (2001). Crafting a job: Revisioning employees as active crafters of their work. Academy of Management Review, 26, 179-201.

\section{Appendix A}

Scale Analyses

\section{Psychometric Qualities}

Cronbach's alphas for all scales and subgroups range from .70 to .93 , meeting the requirements of confirmatory factor analysis (CFA). To evaluate model fit, we applied the usual cutoffs of 3.0 for relative chi square, .90 for comparative fit indices (incremental fit index [IFI], Tucker-Lewis Index [TLI], comparative fit index [CFI]), and .08 for root-mean-square error of approximation (RMSEA), for which we also report $95 \%$ confidence intervals (CIs). In the first step, multi-group CFAs assessed the factor structure of the i-deals measures and the remaining four multi-item scales separately. In both cases, the hypothesized factor structure showed good fit, while the undiscriminating one-factor solutions did not. Similar results were obtained when all six scales were combined into one multi-group CFA (see Table A1).

\section{Measurement Invariance}

To test if combining subgroups is justified, we assessed factorloading invariance by setting path coefficients equal across groups in the multi-group CFAs. Following Byrne (1998), we did not impose equality constraints on the covariances and error terms to avoid being overly restrictive. Model comparisons used significance of the chi-square statistic and change in CFI, which should be below .10 (Cheung \& Rensvold, 2002; Lievens, \& Anseel, 2004). Equality constraints on factor weights did not significantly impede model fit for any of the tested measurement models, indicating that common meaning exists across subgroups. Therefore, combining them into a single sample is legitimate.

\section{Common Method Variance}

Combining all observations into one sample $(N=887)$, we tested the hypothesized six-factor solution against a one-factor model. As in previous analyses, our fit indices show the inadequacy of a one-factor solution, affirming that common method variance does not undermine the empirical distinctiveness of our constructs. For a more rigorous test, we combined those two models by adding an unmeasured single latent method factor connecting all items into the six-factor measurement model (Podsakoff, MacKenzie, Lee, \& Podsakoff, 2003). This addition significantly decreases the chi-square statistic, which is influenced by sample size and reductions in model parsimony (Table A1). However, the addition of the latent method factor did not alter the significance of factor loadings and covariances nor do any items load significantly on it. We conclude that the validity of our results is not threatened by common method bias. 


\begin{tabular}{|c|c|c|c|c|c|c|c|c|c|c|}
\hline CFA & $x^{2}$ & $d f$ & $\chi^{2} / d f$ & IFI & TLI & CFI & RMSEA & $95 \% \mathrm{CI}$ & $\Delta d f$ & $\Delta \chi^{2}$ \\
\hline \multicolumn{11}{|l|}{ Multi-group CFAs $(N=106 / 130 / 206 / 445)$} \\
\hline I-deals: 1 factor, unconstrained & $626.50^{* *}$ & 48 & 13.05 & .75 & .68 & .75 & .117 & $.109, .125^{* *}$ & & \\
\hline I-deals: 2 factors, unconstrained & $106.77^{* *}$ & 44 & 2.43 & .97 & .96 & .97 & .040 & $.031, .050$ & & \\
\hline I-deals: 2 factors, equal meas. weights & $90.56^{* *}$ & 32 & 2.83 & .98 & .95 & .97 & .046 & $.035, .057$ & 12 & 16.21 \\
\hline Other scales: 1 factor, unconstrained & $5,258.37^{* *}$ & 680 & 7.73 & .41 & .34 & .41 & .087 & $.085, .090^{* *}$ & & \\
\hline Other scales: 4 factors, unconstrained & $1,028.56^{* *}$ & 656 & 1.57 & .95 & .94 & .95 & .025 & $.022, .028$ & & \\
\hline Other scales: 4 factors, equal meas. weights & $1,070.64^{* *}$ & 704 & 1.52 & .95 & .95 & .95 & .024 & $.021, .027$ & 48 & 42.08 \\
\hline All scales: 1 factor, unconstrained & $9,216.49^{* *}$ & 1224 & 7.53 & .22 & .17 & .21 & .086 & $.084, .088^{* * *}$ & & \\
\hline All scales: 6 factors, unconstrained & $1,699.11^{* *}$ & 1136 & 1.50 & .95 & .94 & .95 & .024 & $.021, .026$ & & \\
\hline All scales: 6 factors, equal meas. weights & $1,760.44^{* *}$ & 1196 & 1.47 & .95 & .94 & .95 & .023 & $.021, .025$ & 60 & 61.32 \\
\hline \multicolumn{11}{|l|}{ CFAs in combined sample $(N=887)$} \\
\hline All scales: 1 factor & $7,205.61^{* *}$ & 299 & 24.10 & .33 & .27 & .33 & .161 & $.158, .165^{* *}$ & & \\
\hline All scales: 6 factors & $663.12^{* *}$ & 284 & 2.34 & .93 & .96 & .96 & .039 & $.035, .043$ & & \\
\hline All scales: 6 factors, common methods factor & $596.93^{* *}$ & 258 & 2.21 & .97 & .96 & .97 & .037 & $.033, .041$ & 26 & $93.27^{* *}$ \\
\hline
\end{tabular}

\section{Appendix B}

\section{Alternative Model Testing}

We tested our model against four plausible alternatives (Table B1). PI and the more variable work practices of part-time and telecommuting were modeled as outcomes of i-deals (alternative models 1 and 2). For both models, the chi square shows significantly worse fit, with model 2 yielding an uninterpretable solution due to consistently low comparative fit indices (IFI, CLI, TLI). In model 1 , neither flexibility i-deals ( $\beta=.07$, $n s)$ nor developmental i-deals $(\beta=.07, n s)$ predicted PI. Next, all postulated outcomes were modeled as antecedents and as mediators between the controls and work practices on the one hand and i-deals on the other (alternative model 3 and 4). Whereas differences in CFI do not allow for discriminating model fit, model 4 has a significantly higher chi-square discrepancy than does the postulated model. Only alternative model 3, where all variables predict i-deals, shows a significantly lower chi-square. This improvement, however, is attributable to the large num- ber of unanalyzed correlations (undirected paths) among independent variables and decreased model parsimony, which is known to inflate model fit. Table B1 also provides the parsimony ratio (p-ratio), with lower values indicating more complex models. As the rule of parsimony in structural equation modeling generally advises researchers to discard complex models in favor of equally plausible, more parsimonious ones (Kline, 1998; Preacher, 2006), model 3 is not a preferred solution. Additionally, fewer of the structural paths in the model attain statistical significance, and its pattern of effects is inconclusive (e.g., a negative effect of work-family conflict on developmental i-deals, but no effect on flexibility i-deals). As can be inferred from the other three alternative models, reversing causality for the postulated antecedents and outcomes of i-deals does not yield better fit. In sum, the evidence from alternative model testing remains consistent with our theoretical assumptions.

Table B1

Results of Alternative Model Testing

\begin{tabular}{|c|c|c|c|c|c|c|c|c|c|c|c|}
\hline Model & $\chi^{2}$ & $d f$ & $\chi^{2} / d f$ & IFI & TLI & CFI & RMSEA & $95 \% \mathrm{CI}$ & $p$ ratio & $\Delta d f$ & $\Delta \chi^{2}$ \\
\hline Postulated model & $1,323.68^{* *}$ & 435 & 3.04 & .92 & .91 & .92 & .048 & $.045, .051$ & .82 & & \\
\hline Alternative model $1^{\mathrm{a}}$ & $1,372.33^{* *}$ & 440 & 3.12 & .92 & .90 & .92 & .049 & $.046, .052$ & .83 & 5 & $48.65^{* *}$ \\
\hline Alternative model $2^{\mathrm{b}}$ & $1,666.46^{* *}$ & 444 & 3.75 & .89 & .87 & .89 & .056 & $.053, .059$ & .84 & 9 & $342.78^{* *}$ \\
\hline Alternative model $3^{c}$ & $1,049.91^{\text {** }}$ & 405 & 2.59 & .95 & .93 & .94 & .042 & $.039, .046$ & .77 & 20 & $273.77^{\text {** }}$ \\
\hline Alternative model $4^{\mathrm{d}}$ & $1,437.97^{* *}$ & 423 & 3.39 & .91 & .89 & .91 & .052 & $.049, .055$ & .80 & 10 & $114.29^{* * *}$ \\
\hline
\end{tabular}

a Personal Initiative as outcome of i-deals

b Part-Time and Telecommuting as outcomes of i-deals

${ }^{\mathrm{c}}$ Work-Family Conflict, Affective Commitment, Overtime, Increased Performance Expectations as antecedents of i-deals, correlating independent variables

${ }^{\mathrm{d}}$ Work-Family Conflict, Affective Commitment, Overtime, Increased Performance Expectations, and Personal Initiative mediating between Age, Gender, Part-Time, Telecommuting, Fieldwork and i-deals

Note. $\quad$ IFI $=$ incremental fit index; TLI = Tucker-Lewis index; CFI = comparative fit index; RMSEA = root-mean-square error of approximation; CI = confidence interval. 